\title{
E1 Sistema Nacional Anticorrupción mexicano en El Libro Vaquero. Deficiencia estructural y solapamiento de responsabilidades
}

\author{
The Mexican Anti-Corruption National \\ System in E1 Libro Vaquero. Structural \\ deficiency and responsabilities overlapping
}

\author{
Laura Nallely Hernández Nieto \\ Iván Facundo Rubinstein
}

Universidad Nacional Autónoma de México

Laura Nallely Hernández Nieto es licenciada en Comunicación Social por la Universidad Autónoma Metropolitana (UAM) y doctora en Historia del Arte por la Universidad Nacional Autónoma de México (UNAM). Sus áreas de interés son la caricatura y la historieta mexicana, y se ha enfocado en el estudio de la obra de Gabriel Vargas. Ha participado en eventos de diversos congresos internacionales en Argentina, Ecuador, Inglaterra, Colombia, Canadá y Alemania. Recientemente participó en el libro México: 200 años de imágenes e imaginarios civicos publicado en 2017.

Iván Facundo Rubinstein es licenciado en Ciencias de la Comunicación Social por la Universidad de Buenos Aires (UBA) y maestro en Comunicación por la Universidad Nacional Autónoma de México (UNAM), institución en donde se encuentra realizando el Doctorado en Ciencias Políticas y Sociales. Docente en diversas instituciones educativas. Miembro de la Federación Latinoamericana de Semiótica (FELS) y del Global Alliance for Media and Gender (GAMAG). Ha participado en congresos nacionales e internacionales y publicado en journals y revistas especializadas. Sus áreas de interés abarcan el análisis del discurso, la comunicación política y las industrias culturales.

Fecha de recepción: 21 de noviembre de 2017

Fecha de aceptación definitiva: 10 de agosto de 2018 


\title{
Resumen
}

El presente artículo indaga en la construcción discursiva del llamado Libro Vaquero Anticorrupción a través del análisis socio-semiótico de su estructura formal, su narrativa y su modo de abordar el lanzamiento del Sistema Nacional Anticorrupción (SNA) en México. La principal conclusión a la que se arriba es que el discurso oficial del SNA responsabiliza de forma casi exclusiva a la sociedad civil por las condiciones actuales en relación a la corrupción. De esta forma, se invisibilizan las causas estructurales, principalmente en relación a los actores del campo de poder (entendido como la conjunción del campo político y económico).

Palabras clave: Cómic mexicano, comunicación política, Libro Vaquero Anticorrupción, semiótica, Sistema Nacional Anticorrupción

\begin{abstract}
In this article we analized the discourse construction of the so called Libro Vaquero Anticorrupción (Anti-corruption Cowboy Book) through the socio-semiotic analysis of its formal structure, its narrative and its way of represent the launch of the Mexican Anti-corruption National System (SNA by its Spanish initials). In the comic, the official discourse of SNA blame on society for the current problems in relation with corruption. Thus, the structural causes are set aside, principally in relation with the actors of the power field (i.e.: the politic and the economic fields).
\end{abstract}

Keywords: Mexican comic, Libro Vaquero Anticorrupción, Anti-corruption National System, political communication, semiotics

\section{Cita bibliográfica}

Hernández Nieto, L. N. y Rubinstein, I. F. «El Sistema Nacional Anticorrupción mexicano en El Libro Vaquero. Deficiencia estructural y solapamiento de responsabilidades», en CuCo, Cuadernos de cómic, n. ${ }^{\circ} 11$ (2018), pp. 30-51. 


\section{Introducción}

El propósito de la presente investigación es analizar la forma en que se presenta el Sistema Nacional Anticorrupción - cuyas siglas son SNA - en uno de las historietas mexicanas de mayor circulación: El Libro Vaquero. El contexto en el que se produce está caracterizado por un prolongado malestar social respecto del gobierno mexicano, y la consecuente crisis de credibilidad hacia la clase dirigente. Dados los bajos niveles de lectura que presenta la población mexicana y el desconocimiento general respecto de dicho Sistema, el estado decidió apuntalar la campaña con la difusión de una breve historieta confeccionada ad hoc, la cual permitiera llegar a aquellos sectores marginales y poco interesados en las cuestiones políticas.

Para llevar adelante esta investigación se utilizaron herramientas provenientes de la socio-semiótica, a fin de poder trabajar directamente sobre los procesos de producción de sentido que operan en la historieta. Partiendo de un análisis formal, se examinaron los rasgos retóricos de la historieta, particularmente aquellos de naturaleza estilística, y su incidencia en el género narrativo al cual se adscribe. Asimismo, se examinaron las dimensiones enunciativa y referencial, particularmente en relación a la representación del SNA. La principal conclusión a la que se arriba es que el discurso oficial presente en la revista responsabiliza de forma casi exclusiva a la sociedad civil por las condiciones actuales en relación a la corrupción. De esta forma, quedan invisibilizadas las causas estructurales, principalmente en relación con los actores del campo de poder (entendido como la conjunción del campo político y el campo económico).

\section{Lanzamiento de El Libro Anticorrupción}

El 1 de marzo de 2017 se presentó en la Cámara de Diputados El Libro Anticorrupción (historieta incluida en la revista El Libro Vaquero), ${ }^{1}$ publicación que estuvo a cargo de la consultora Ethos con el apoyo del Caucus Anticorrupción, grupo conformado por diversos legisladores que se presentaban como especialistas en transparencia y rendición de cuentas. El objetivo, según se dijo en la conferencia de prensa, era «desalentar la mordida ${ }^{2}$ y promo-

${ }^{1}$ El Libro Vaquero es una historieta mexicana creada por Rafael Márquez en 1978. En ella se abordan historias ambientadas en un viejo oeste mexicanizado donde los protagonistas son indios y vaqueros.

${ }^{2}$ Mordida: soborno, en sentido coloquial. 
ver la denuncia ciudadana». ${ }^{3}$ Este evento se produjo en el marco de la implementación del SNA — sancionado por la LXII Legislatura a través de la reforma constitucional del 2015y en un contexto social de pérdida de credibilidad del ámbito político, especialmente de los partidos tradicionales. ${ }^{4}$

La consultora Ethos se describe en su página como un «laboratorio de ideas (Think tank) que transforma investigaciones y experiencias en recomendaciones claras y acciones concretas de política pública que atienden los problemas más relevantes y los principales retos para el desarrollo y progreso de México y América Latina». En una entrevista radiofónica en W Radio, el día 2 de marzo, José Luis Chicoma, director general de la consultora señaló:

\begin{abstract}
Muchos pensamos que la fiscalía anticorrupción, todo el entramado de instituciones que se aprobaron con la reforma anticorrupción reciente del año pasado, era lo más importante que comunicar a la ciudadanía. Teníamos como misión eso, comunicar qué significaba el Sistema Nacional Anticorrupción [...] esta es, digamos, la primera parte de un conjunto de historietas que pensamos hacer. Será, creo, algo aleccionador para todos. ${ }^{5}$
\end{abstract}

La edición especial contó con veinte mil ejemplares y se distribuyó de forma gratuita en estaciones de metro e instituciones educativas como la Universidad Nacional Autónoma de México (UNAM) y La Salle. Además, la historia se incluyó en la edición quincenal de la revista correspondiente al 15 de febrero de 2017. En redes sociales, a través del hashtag \#LibroVaqueroAnticorrupción se invitó a la población en general a formar parte de las brigadas de distribución que estuvieron apostadas en distintos puntos de la Ciudad de México.

De acuerdo con un artículo publicado en la revista Expansión en 2015: «el costo de producción de estos cómics empresariales es de entre 100000 y 200000 pesos» ${ }^{6}$ (aproximadamente entre U\$D 5500 y U\$D 11 000), según datos proporcionados por la constructora ICA, quien mandó hacer una historieta sobre seguridad en el trabajo. Con esta cifra se tiene una idea - tan solo una idea - del precio que cobra la editorial por realizar este tipo de trabajo, ya que el monto final de El Libro Anticorrupción nunca fue revelado.

3 Animal Político. «¿Un Libro Vaquero para entender (y combatir) la corrupción?», en Animal Político, 1 de marzo de 2017. Disponible en http://www.animalpolitico.com/2017/03/libro-vaquero-corrupcion/

4 A modo puramente ilustrativo es posible mencionar el escándalo de la «Casa Blanca» que involucró al presidente y a su esposa (2014), la casa del secretario de Hacienda, Videgaray (2014), la imputación y posterior fuga del gobernador de Veracruz, Javier Duarte (2016) y las acusaciones a diversos gobernadores: Guillermo Padrés (Sonora), Cesar Duarte (Chihuahua) y Humberto Moreira (Coahuila).

5 Warketin, G. y Risco A. El Libro Vaquero está de regreso [Podcast]. Programa Así las cosas, W radio, 2 de marzo de 2017. Disponible en http://ethos.org.mx/es/el-libro-vaquero-esta-de-regreso/

${ }^{6} \mathrm{El}$ mismo artículo menciona que «HeVi Editores no revela cifras de sus negocios». Murillo, C. «El Makeover del Vaquero», en Revista Expansión, 9-22 de octubre de 2015. Disponible en https://issuu.com/ ellibrovaquero/docs/exp-1176-libro vaquero 


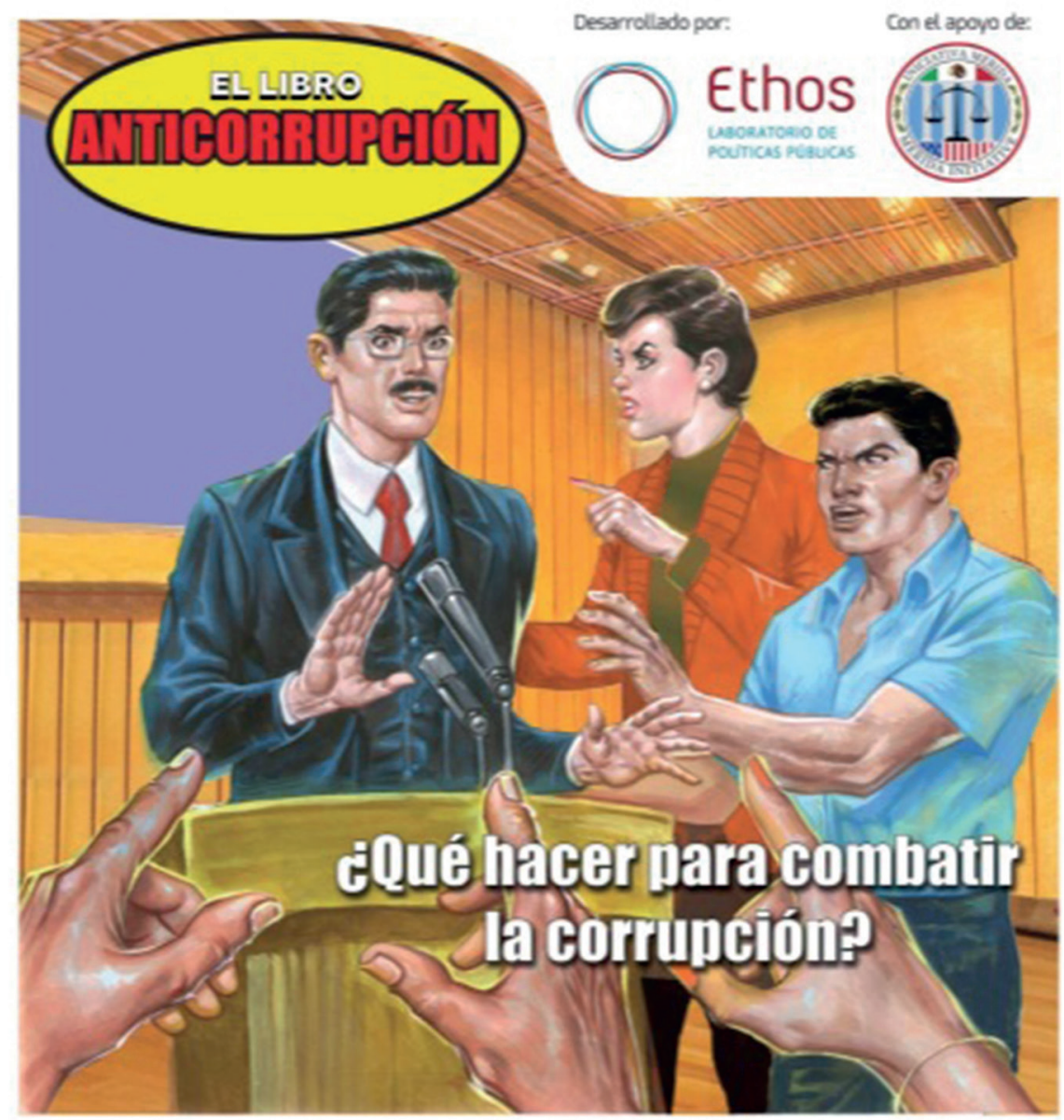

FIG. 1. Portada del suplemento El Libro Anticorrupción publicado dentro de la revista El Libro Vaquero, $\mathrm{HeVi}, 15$ de febrero de 2017.

\section{Antecedentes}

$\mathrm{El}$ inicio de las historietas mexicanas modernas coincide con el término de la fase armada de la Revolución (1917). Estas series inundaron las páginas de los suplementos dominicales de periódicos como El Heraldo, El Demócrata, El Universal y El País, donde se publicaron desde 1919 hasta mediados de los años treinta.

El pueblo mexicano se inició en la lectura precisamente con las historietas. A finales de los treinta y durante la década de los cuarenta, millones de compatriotas, que aún no habían experimentado los placeres de la letra impresa, perdieron su virginidad literaria sumergiéndose en las seductoras páginas de las revistas de «monitos». ${ }^{7}$

7 Aurrecoechea,J. M.y Bartra, A. Puros cuentos. La historia de la historieta en México 1934- 1950. México, Conaculta - Grijalbo, 1993, p. 13. («Monitos»: forma coloquial de llamar a las historietas en México). 
La época de oro de la historieta mexicana se inicia una década después, en 1934, «lapso en el que aumento de la alfabetización confluye con la proliferación de revistas de cómics de factura nacional». ${ }^{8}$ Paquin fue la primera revista de «monitos»; a esta le siguieron Pepin, Paquito, Pinocho y Chamaco. Casi todas estas publicaciones aparecían diariamente e, incluso, llegaban a tirar dos ediciones los domingos. El auge terminó en los primeros años de la década de los cincuenta, con la desaparición de estas revistas. Posteriormente llegó un «segundo aire» de la historieta mexicana al que se denominó «época de plata», periodo que se dio desde mediados de 1950 y culminó al inicio de los años ochenta. De esta etapa destacaron títulos como Kalimán, Chanoc, Lágrimas y Risas, Hermelinda Linda, El Pantera, etcétera. De esta última fase exitosa de la historieta mexicana sobrevive El Libro Vaquero, que se publica desde el 23 de noviembre de 1978; esta fue la primera revista que se editó en formato de bolsillo (13 x 15.5 centímetros) y a color. La historieta, creada por Rafael Márquez, está ambientada en un «viejo oeste mexicanizado» y en sus páginas se narran episodios sobre duelos a muerte, intrigas y pasiones; una de sus características es el mostrar en los dibujos a mujeres voluptuosas sin llegar a los desnudos totales. Durante estos años, la revista ha pertenecido a Novedades Editores, Ciesa y actualmente es propiedad de la empresa $\mathrm{HeVi}$, donde tiene un tiraje de 118000 ejemplares y ofrece un nuevo episodio cada quince días.

Aunque El Libro Vaquero ha sido una lectura denostada, ya que su precio es muy accesible por la baja calidad del papel en sus interiores, esta historieta es parte de la cultura popular de México. Desde sus inicios, la revista estuvo asociada a las clases populares a quienes se les caracterizaba, entre otras cosas, por practicar lectura de «baja calidad». Este imaginario perdura hasta el día de hoy. Por ejemplo:

A finales de 2011, en las redes sociales apareció una imagen del entonces precandidato presidencial de la Coalición por México (PRI-PVEM), Enrique Peña Nieto, sosteniendo un ejemplar del Libro Vaquero, como burla por su incapacidad para citar el título de tres libros que marcaron su vida. ${ }^{9}$

Esta visión sobre la revista ocasionó, por ejemplo, que en 2005 la Biblioteca Pública de Denver, Estados Unidos, cancelara la suscripción a cuatro títulos de historietas en español - entre ellas El Libro Vaquero - por considerar que tenían un contenido con imágenes sexualmente explicitas, hecho improbable, ya que una de las principales políticas de Márquez fue siempre evitarlas (además, cabe señalar que si bien la revista no maneja un contenido de alta complejidad, ofrece un texto cuidado en su redacción y ortografía). El suceso «fue visto como un gesto de discriminación a la cultura popular mexicana». ${ }^{10}$ Lo anterior, sin

${ }^{8}$ Camacho Morfín, T. «Dibujar historietas. Una enseñanza fuera de la Academia», en Reyes, A. (coord.). La enseñanza del dibujo en México, Aguascalientes, Universidad Autónoma de Aguascalientes, 2014. p. 339.

9 Ocampo, M. «Libro Vaquero: odiado y amado, sigue galopando» en Sin Embargo, 12 de abril de 2013. Disponible en http://www.sinembargo.mx/12-04-2013/583742

10 Associated Press. «La Biblioteca Pública de Denver veta las historietas El Libro Vaquero, El Libro Policiaco y otras dos» en La Crónica, 26 de agosto de 2005. Disponible en http://www.cronica.com.mx/ notas/2005/198922.html 
embargo, contrasta con el recibimiento que tuvo la publicación en Europa: en 2012 se exhibieron portadas e ilustraciones originales de El Libro Vaquero en la exposición The good, the bad and the sexy, en la galería Divis Prager Kabarett, en Praga, Republica Checa. ${ }^{11}$ Este tipo de valoraciones antagónicas por parte de museos en América y Europa es un signo de la complejidad que rodea a esta historieta: en relación con la cultura canónica, es considerada como un objeto sin valor, producido por una industria cultural que se beneficia de la semi-alfabetización de la población que sufre rezago educativo; en relación con las clases populares, es un producto cultural que ha sabido sobrevivir casi medio siglo, y que no da señales de desaparecer. Es un producto, en fin, que conjuga tanto una dimensión estética como una cultural, sociológica y, como veremos en este artículo, política. He ahí su importancia como objeto de estudio.

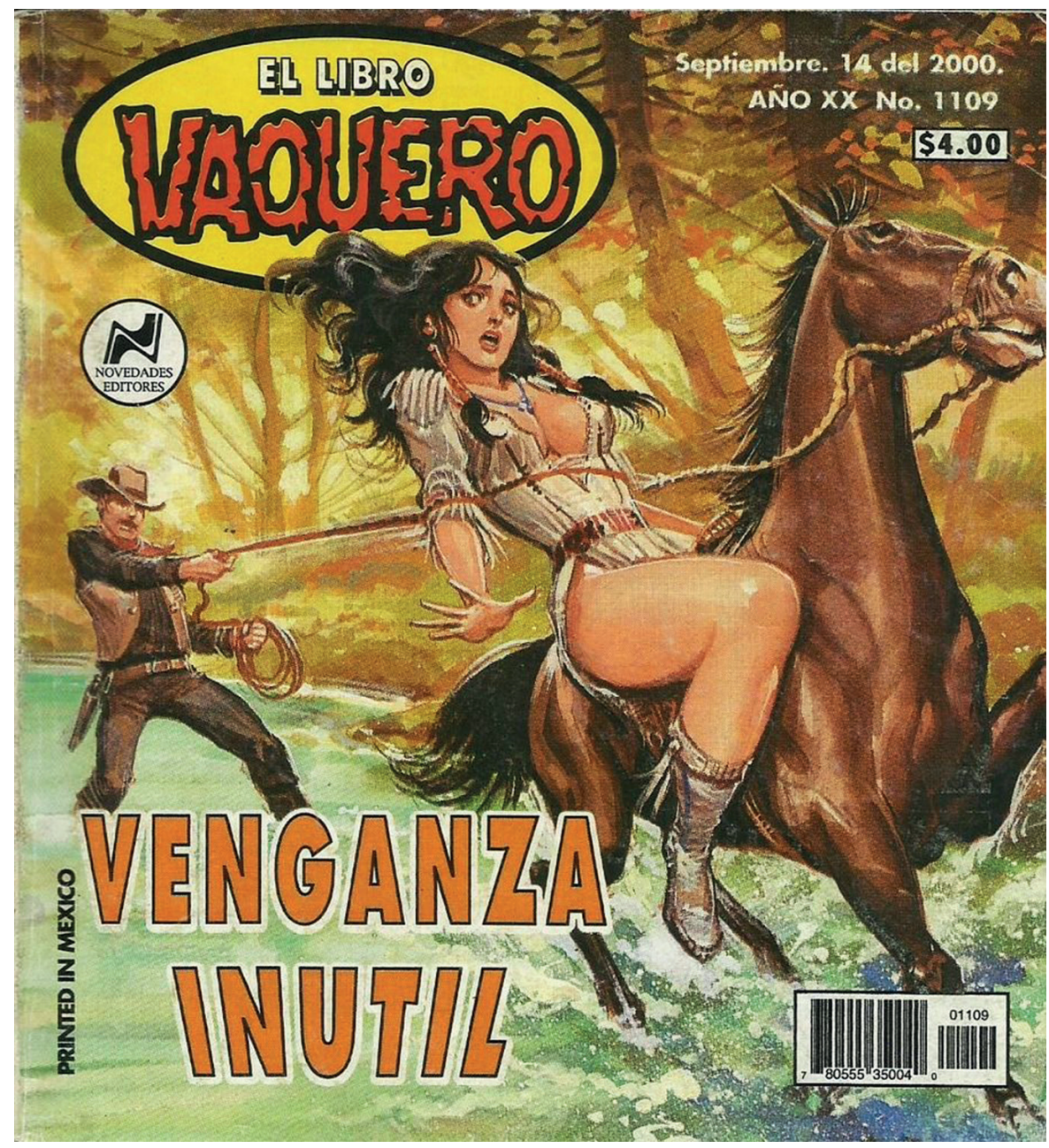

FIG. 2. Ejemplo de las portadas que caracterizan a El Libro Vaquero. Novedades Editores, 14 de septiembre del 2000.

11 NúñEz, G. El Libro Vaquero mexicano seduce en Praga. [Podcast]. Radio Praha en español, 27 junio de 2012. Disponible en http://www.radio.cz/es/rubrica/panorama/el-libro-vaquero-mexicano-seduce-en-praga 
Desde el 2015 la revista ha tratado de atraer a un público joven: «veinteañeros, hipsters, fanáticos de lo kitsch o folclórico mexicano», ${ }^{12}$ según declaró en una entrevista Antonio Reyes Luna, CEO de la Editorial HeVi. En ese año, las investigaciones cualitativas de la empresa arrojaron que el público tradicional de esta historieta eran mexicanos de nivel socioeconómico medio bajo y bajo, que representaban el $46 \%$ de sus lectores; $21 \%$ eran de clase media alta y $2 \%$ de clase alta. Casi el $70 \%$ eran hombres. ${ }^{13}$

En ese tenor, se lanzaron las ediciones especiales tituladas «Grandes escritores». El primero de estos episodios estuvo a cargo del escritor Jordi Soler, quien escribió «La ley y el opio» y la segunda edición fue escrita por Yuri Herrera, quien colaboró con «Un capitán cimarrón». ${ }^{14}$ Uno de los motivos principales que favoreció la incursión de escritores de cuentos y novelas en la narrativa de El Libro Vaquero fue "corromper la estúpida idea de que los "grandes autores" solo escriben para una población más o menos "culta”, y de que, a su vez, las masas no leen lo que se ofrece en las librerías». ${ }^{15}$ Esta renovación no ha cambiado el dibujo: aunque ahora el color se agrega de manera digital, prácticamente toda la revista se sigue haciendo a mano. Asimismo, la portada se continúa realizando con técnica wash y sin retoques, la cual han usada desde el primer número y que hace que los lectores identifiquen a la publicación. ${ }^{16}$

Desde su aparición, las historietas se han utilizado como recurso educativo, como material didáctico o como una forma de publicidad (como fue el caso de la cigarrera El Buen Tono, a principios del siglo pasado). Sin embargo, en la mayoría de los casos no se toma en cuenta que

no se trata de una mera yuxtaposición de texto e imagen [...] La ignorancia de esta premisa, tal vez no en concepto, pero si en su aplicación práctica, motiva que la gran mayoría de estas obras realizadas por autores de guiones no directamente vinculados con el medio - sirva como ejemplo el $90 \%$ de las «historias de...» patrocinadas por ayuntamientos y comunidades autónomas - sean farragosas y poco directas en su modo de narrar y se reduzcan en la mayor parte de los casos a textos ilustrados con algún que otro bocadillo a modo de adorno. ${ }^{17}$

El Libro Vaquero ha sido usado como una herramienta para llegar a un segmento de mercado específico, con diversas ediciones especiales, realizadas por encargo de diversas instituciones públicas y privadas. En 2004 la Secretaría de Relaciones Exteriores (SRE) distribuyó un millón y medio de ejemplares de la Guía del Migrante Mexicano en El Libro Vaquero y El

${ }_{12}$ Murillo, C. Op.cit., p. 74.

13 Idem.

${ }^{14}$ Liceaga, E. «Libros Vaqueros», en Letras Libres, 13 de noviembre de 2015. Disponible en http://www. letraslibres.com/mexico-espana/libros-vaqueros

15 Liceaga, E. Op.cit.

16 Toca G., V. «El Libro Vaquero, el western mexicano más leído», en Revista Expansión, 22 de abril de 2012. Disponible en https://expansion.mx/entretenimiento/2012/04/22/el-libro-vaquero-el-western-mexicano-mas-leido

17 Rodríguez Beltrán, J. L. «Análisis de los problemas expresivos del cómic», en Revista Interuniversitaria de didáctica. 2009, p. 150. Disponible en http://revistas.usal.es/index.php/0212-5374/article/view/4174 
Libro Semanal, donde se alertaba sobre los riesgos de intentar cruzar la frontera. «El proyecto para su diseño y maquila fue asignado a Niesa [empresa donde se publicaba la revista] y el contenido lo hizo la Cancillería. Los estadounidenses vieron en la guía una clara incitación a la migración, presionaron para cancelar el proyecto, pero no lo consiguieron. Incluso el Congreso respaldó una reimpresión». ${ }^{18}$

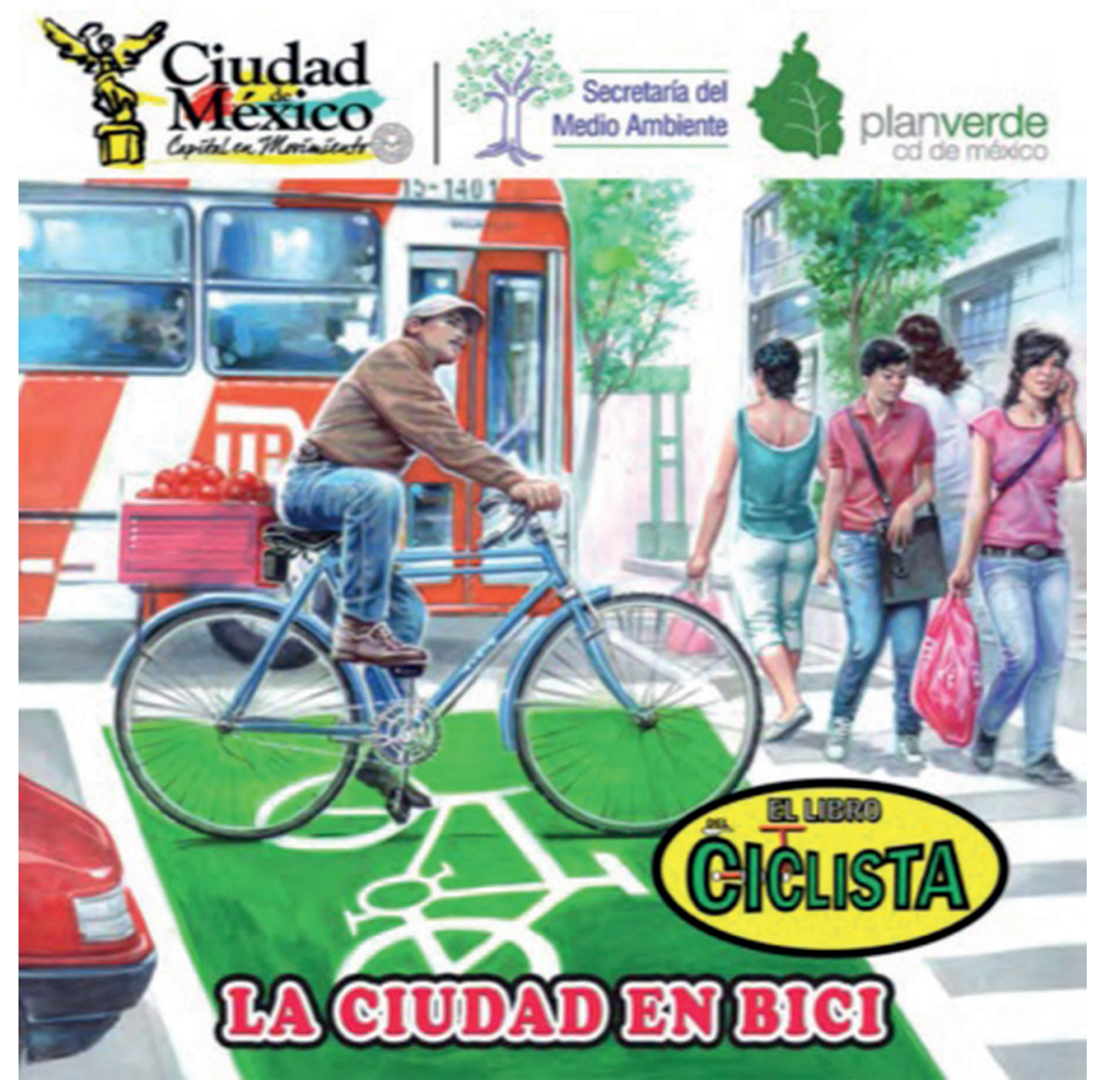

FIG. 3. Manual del servicio Ecobici, $\mathrm{HeVi}, 25$ de agosto de 2015 .

Desde 2010, la revista hace historietas para empresas y entidades gubernamentales, servicio conocido como custom publishing. ${ }^{19}$ Es así como dentro de la revista El Libro Vaquero se publicó un suplemento sobre la reforma energética, encargado por el Gobierno de la República; la edición titulada «Alimentos sanos y de calidad a tu mesa», realizada para la campaña «Vivir Mejor», de la Secretaria de Agricultura, Ganadería, Desarrollo Rural, Pesca y Alimentación

\footnotetext{
18 López Parra, R. «El Libro Vaquero, un clásico de la cultura popular», en Revista Mexicana de Comunicación, n. ${ }^{\circ} 99$, junio - julio de 2005. Disponible en http://mexicanadecomunicacion.com.mx/rmc/2012/06/25/ el-libro-vaquero-un-clasico-de-la-cultura-popular/

${ }_{19}$ Murillo, C. Op.cit., p. 74.
} 
(Sagarpa); un manual de uso del servicio Ecobici para la campaña «Plan Verde», del gobierno de la Ciudad de México; la edición «Con agua crecida cuida tu vida», encargada por la Comisión Nacional del Agua (CONAGUA); y los episodios titulados «Por nuestras lenguas indígenas», $y$ «Orgullo por escuchar a México», en colaboración con el Instituto Nacional de Lenguas Indígenas (INALI). Asimismo, ha realizado encargos para diferentes empresas: «Prevención es vida», encargado por Ingenieros Civiles Asociados (ICA); «Los colores de la vida», por la empresa de pinturas Comex; $\mathrm{y}$ «El guardián de tu prestigio», por la empresa de seguridad privada Flow Guard. Finalmente, cabe señalar que los servicios de $\mathrm{HeVi}$ han sido solicitados por dos candidatos presidenciales: el candidato del partido Nueva Alianza, Gabriel Quadri, en 2012 («La Nueva Alianza es contigo»); y el candidato de la coalición Todos por México, José Antonio Meade («Juntos por México») en 2018.

Cabe aclarar que la relación entre los políticos y El Libro Vaquero no se limita a la publicación de números por encargo. En el año 2015, cuando Jaime «El Bronco» Rodríguez se presentaba como candidato independiente para la gubernatura del estado de Nuevo León, señaló que su lectura favorita era El Libro Vaquero; afirmación que repitió al presentar su autobiografía, escrita por su amigo y periodista Rubén Darío Bernal..$^{20}$

Asimismo, se pueden mencionar algunos antecedentes inmediatos que ilustran la importancia de la historieta para el campo político mexicano. En el año 2000, el candidato del Partido Revolucionario Institucional (PRI), Francisco Labastida Ochoa, editó una historieta a modo de biografía ilustrada, titulada Una vida ejemplar. Lo mismo hizo en la siguiente campaña (en el año 2006) el candidato por el Partido de la Revolución Democrática (PRD), Andrés Manuel López Obrador, al lanzar tres números de una historieta titulada PGman, el indestructible, ${ }^{21}$ con un tiraje aproximado de dos millones doscientos mil ejemplares por cada número. También puede mencionarse la tira El México que queremos, financiada por el Consejo Coordinador Empresarial (CCE) o la historieta de 1997 Más vale prevenir... editada por el Consejo Nacional para la Prevención y el Control del Sida y financiada por la Organización Panamericana de la Salud.

Esta práctica de utilizar las historietas como vehículos para difundir información considerada importante se sustenta en una realidad social. Ya se ha señalado que la valoración general que se tiene de El Libro Vaquero es negativa. Esto encuentra sustento con algunos datos relevantes de la actualidad mexicana: de acuerdo con una encuesta realizada en el 2017 por el Instituto Nacional de Estadística y Geografía (INEGI), titulado Módulo sobre Lectura (MOLEC), ${ }^{22}$ se halló que el 55\% de los encuestados no había leído libros en el último año.

${ }^{20}$ SDPnoticias. «E1 Bronco deja claro que el Libro Vaquero es su favorito», en SDPnoticias.com, 24 de octubre de 2016. Disponible en https://www.sdpnoticias.com/local/nuevo-leon/2016/10/24/el-bronco-deja-claroque-el-libro-vaquero-es-su-favorito

${ }^{21}$ En alusión al sobrenombre de «peje», con el que se conoce popularmente al candidato.

${ }^{22}$ INEGI. «Módulo sobre lectura (Molec). Principales resultados febrero 2017», en Instituto Nacional de Estadistica y Geografía. Disponible en http://internet.contenidos.inegi.org.mx/contenidos/productos/prod serv/contenidos/espanol/bvinegi/productos/nueva estruc/promo/resultados molec feb17.pdf 
Alrededor del 40\% afirmaron haber leído revistas. Dejando de lado el motivo principal para no leer (falta de tiempo, con más del 40\%), el motivo más citado para no hacerlo fue el desinterés (26,8\%). Ante este panorama - población alfabetizada pero que no cuenta con hábitos de lectura fuertemente arraigados- los responsables de poner en funcionamiento el SNA decidieron que la mejor vía para darlo a conocer era a través del canal más frecuentado por las poblaciones marginales: la historieta.

\section{Analizando el SNA en El Libro Anticorrupción. Representaciones discursivas}

A continuación se presenta la trama de la historia, así como las principales consideraciones de tipo formal (principalmente, a través del análisis de las viñetas, las acciones y el empleo de texto) y aquellas que se desprenden de un análisis discursivo. De esta manera, se ofrece un panorama integral del discurso del SNA en El Libro Anticorrupción y el modo en que se articula con el contexto político y social detallado al inicio.

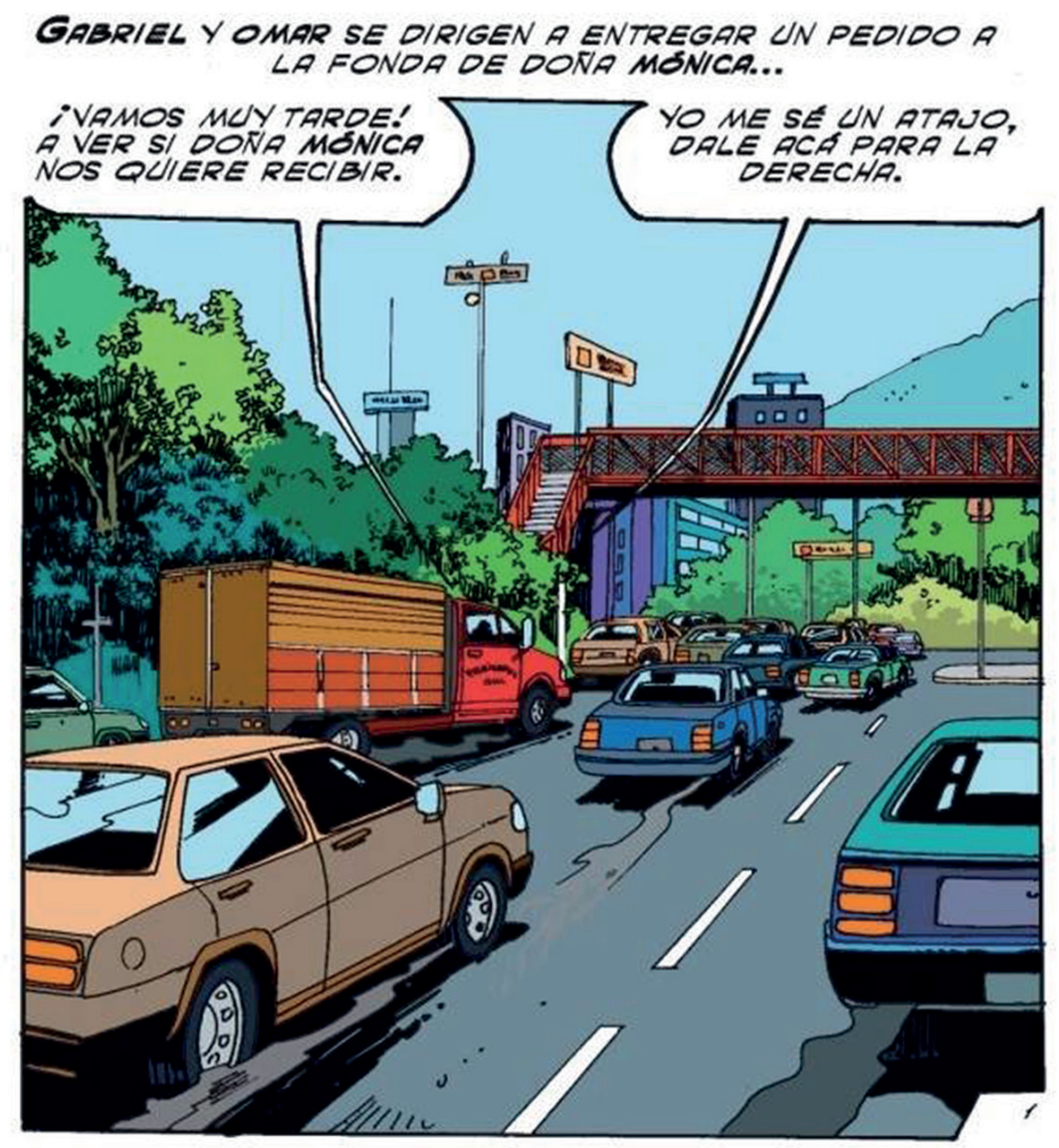

FIG. 4. Ubicación espacial de la historieta, $S u$ plemento especial Libro Anticorrupción, $\mathrm{HeVi}, 15$ de febrero de 2017, p. 1. 
La historia que narra la edición titulada «¿Qué hacer para combatir la corrupción» es la siguiente: Gabriel y Omar, dos jóvenes repartidores, se dirigen a entregar un pedido a la Fonda de Doña Mónica, un pequeño restaurante de comida económica. Como van retrasados, se dan una vuelta en sentido contrario y los detiene una patrulla de tránsito. Después de sobornar al policía, este los deja ir. Mientras tanto, en el establecimiento, Doña Mónica conversa con un hombre sobre los trámites para "poner en orden su negocio» tras las muerte de su marido. En ese instante, aparece una mujer que responde por el nombre de Diana, a quien ella le cuenta que cuando fue a la delegación a preguntar sobre los requisitos para regularizar su local, los servidores públicos le pidieron dinero para poder hacer el trámite. Los repartidores aparecen de nuevo en la historia: ellos justifican su retraso por la detención de la patrulla. Diana los reprende y les explica al resto de los personajes que «todos podemos ser parte de un acto de corrupción». ${ }^{23}$ Después, menciona que con el nuevo SNA los funcionarios podrían ser sancionados por caer en actos de extorsión y concluye con la invitación (a los personajes y a los lectores) a denunciarlos.

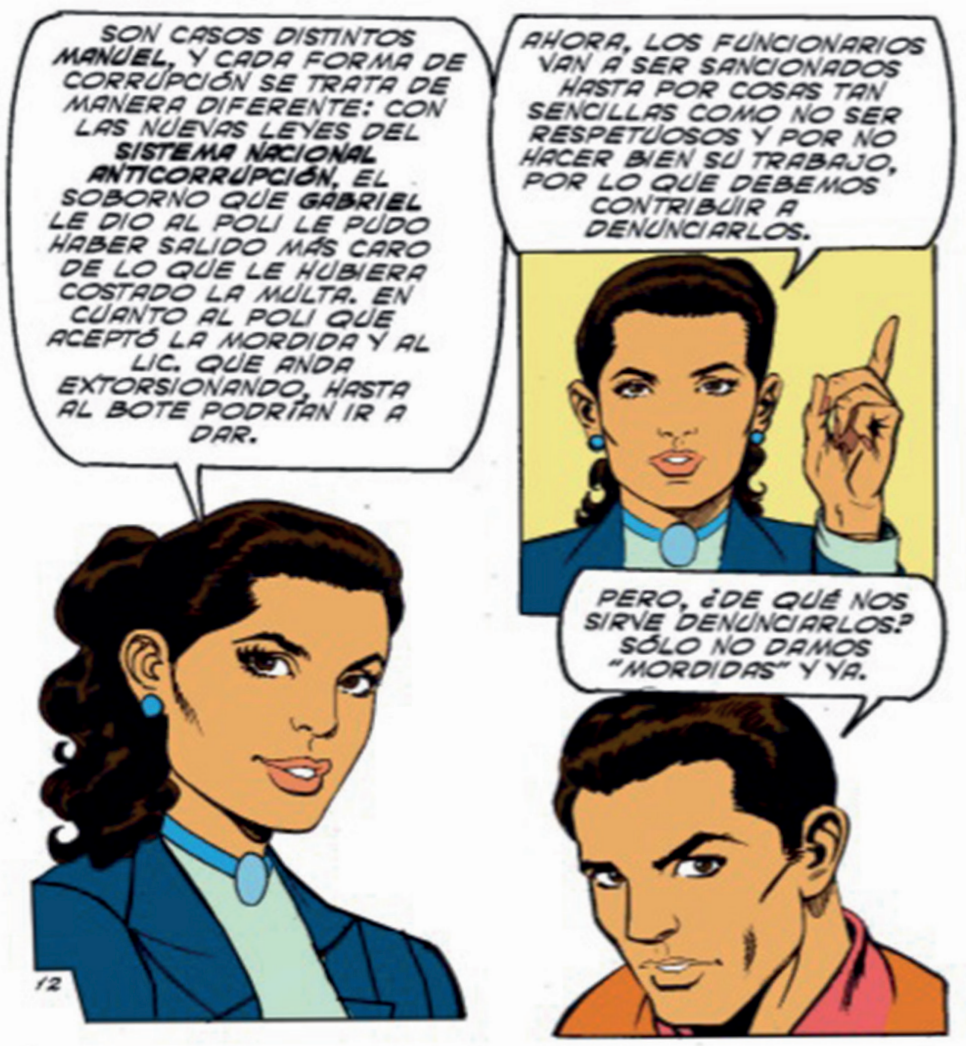

FIG. 5. Discurso de Diana sobre el SNA, Suplemento especial Libro Anticorrupción, $\mathrm{HeVi}, 15$ de febrero de 2017, p. 12.

${ }^{23}$ ETHOS. «Suplemento especial Libro Anticorrupción. ¿Qué hacer para combatir la corrupción?», en El Libro Vaquero, 15 de febrero de 2017, p. 10. 
En cuanto a la ubicación de la trama, la situación presentada sucede en un ambiente urbano. No hay ninguna referencia espacial en el dibujo. El lector puede intuir que se desarrolla en la Ciudad de México ya que se menciona «la delegación», ${ }^{24}$ pero si el lector omite este detalle la historia podría situarse en cualquier urbe de la república. En cuanto a las acciones, estas se desarrollan en dos escenarios: una avenida principal y el negocio de comida.

\section{Rasgos estilisticos}

El Libro Anticorrupción está compuesto por pocas viñetas. Los dibujos presentan una línea clara, son esquemáticos y poseen un tratamiento sencillo; es decir, no hay uso de recursos cinéticos así como tampoco de sombreados, efectos de volumen y degradados de color.

Las carteleras (cuadros de texto que se sitúan en la parte superior de la viñeta) son visualmente pesadas. Debido a la gran cantidad de información que se tiene que dar al lector en este tipo de historias, aparecen saturadas, de la misma forma que los globos de diálogo; esta sobrecarga de texto, cabe señalar, compensa la falta de trama en las historias presentadas.

Todas las viñetas están diagramadas en forma equitativa: hay un espacio para los diálogos y otro para los dibujos, aunque estos son desproporcionados. Por lo tanto, no hay dinamismo. La historia presenta poco uso de encuadres, como ocurre en la página en la que el personaje de Diana habla sobre el SNA. Esta es particularmente estática: presenta un uso pobre de los recursos cinéticos. Parecen dibujos aislados y sin situación, ya que no hay otro encuadre que construya gráficamente otra acción. Si se toma en cuenta que la historieta clásica tiende a ser el vehículo idóneo para fines didácticos ${ }^{25}$ cabe suponer que se mantendrán sus características formales a fin de que la lectura de la misma sea efectiva. No obstante, respecto los rasgos estilísticos, vemos que no es así. En la historieta clásica «cada una de sus imágenes y unidades narrativas guarda una relación de carácter causal con la siguiente, en una secuencia apodíctica, es decir, de necesidad mutua». ${ }^{26}$ Como puede observarse en la Figura 5, no hay relación necesaria entre las imágenes de las viñetas: son solo una yuxtaposición de primeros planos de los personajes, en el vacío: no hay escenario de fondo que ubique espacialmente a la situación. El único elemento que mantiene unidas a las viñetas y les otorga continuidad es el texto: un monólogo por parte de Diana, dividido en dos viñetas, y la consecuente respuesta que suscita.

${ }^{24}$ La Ciudad de México era la única entidad nacional que se subdividía en dieciséis delegaciones (las cuales, a su vez, se subdividen en colonias). A partir de septiembre de 2018, estas delegaciones se convirtieron en demarcaciones territoriales gobernadas por un alcalde y un concejo.

25 Zavala, L. «Los componentes formales, estructurales e ideológicos de la narrativa gráfica», en DeSigns. Semióticas gráficas, n. ${ }^{\circ} 21$ (2013), pp. 72-81.

${ }^{26}$ Ibid., p. 73. 
Es importante destacar que estos rasgos tienen un fuerte impacto en la lectura de la historieta. Si entendemos al género como un horizonte de expectativas que guía la lectura de las producciones discursivas, ${ }^{27}$ podemos ver que lo señalado más arriba afecta a dos de las tres principales dimensiones constitutivas del género en que se inserta la historieta: la retórica y la temática. ${ }^{28}$ La primera, en la medida en que el recorrido de lectura carece del dinamismo que caracteriza a El Libro Vaquero, al tiempo que el componente visual queda relegado a un segundo plano, subordinado al texto. La segunda queda clara en la situación misma de la trama: no se encuentra situada en el Oeste, en el ámbito rural, sino que todos los sucesos tienen lugar en una zona urbana. Sin llegar al punto en que estas cuestiones conviertan a El Libro Anticorrupción en un antigénero - el cual se caracteriza por poseer un quiebre con relación al género en los niveles referencial, enunciativo y estilístico-, ${ }^{29}$ es posible intuir que dificultará la lectura del mismo, al romper el horizonte de expectativas; lo que ocasionaría que el mensaje que pretende transmitirse caiga en el vacío- recordemos que, como mínimo, la historieta tuvo un costo de cien mil o doscientos mil pesos, salidos del erario público.

\section{Personajes}

Un primer punto a destacar es que los personajes femeninos se construyen principalmente a través de estereotipos opuestos que tienden a reforzar la discriminación de clase. La primera en aparecer en la historia es Doña Mónica, la dueña (luego del fallecimiento de su esposo) del pequeño restaurante. Aparece representada con un marcado tono moreno, el cual contrasta con el resto de los personajes. Viste un mandil rosado, el cual aparece en forma marcadamente visible a lo largo de todas las viñetas, lo que refuerza su rol de trabajadora del negocio de comida. Su actitud es una mezcla de servidumbre (o quizás pasividad) y resignación. Tal como afirma Steimberg «cada historieta puede seleccionar el nivel de su proposición interpretativa: puede indicar modos exclusivamente visuales de señalar los estigmas de un sector social o psicológico». ${ }^{30}$ En este caso específico, el principal estereotipo recae sobre Doña Mónica, ya que los otros personajes son representados en forma neutra. Ella, por el contrario, carga con el peso de ser mujer, morena y pobre, ya que, si bien todos los personajes, exceptuando Diana, pertenecen a las clases populares, Doña Mónica tiene un trabajo anclado en su condición de género y posee poca instrucción (a juzgar por sus dificultades para culminar sus trámites); asimismo, podemos señalar el hecho de que, en la trama, ella quedó como dueña del pequeño restaurante solamente tras la muerte de su marido.

${ }^{27}$ Bajtín, M. «El problema de los géneros discursivos», en Estética de la creación verbal. Ciudad de México, Siglo XxI, 1982.

28 Steimberg, O. Semiótica de los medios masivos. El pasaje de los medios a los géneros populares. Buenos Aires, Atuel, 1998.

${ }^{29}$ Ibid., p. 78.

30 Steimberg, O. Leyendo historietas: textos sobre relatos visuales y humor gráfico. Buenos Aires, Eterna Cadencia Editora, 2013, p. 114. 


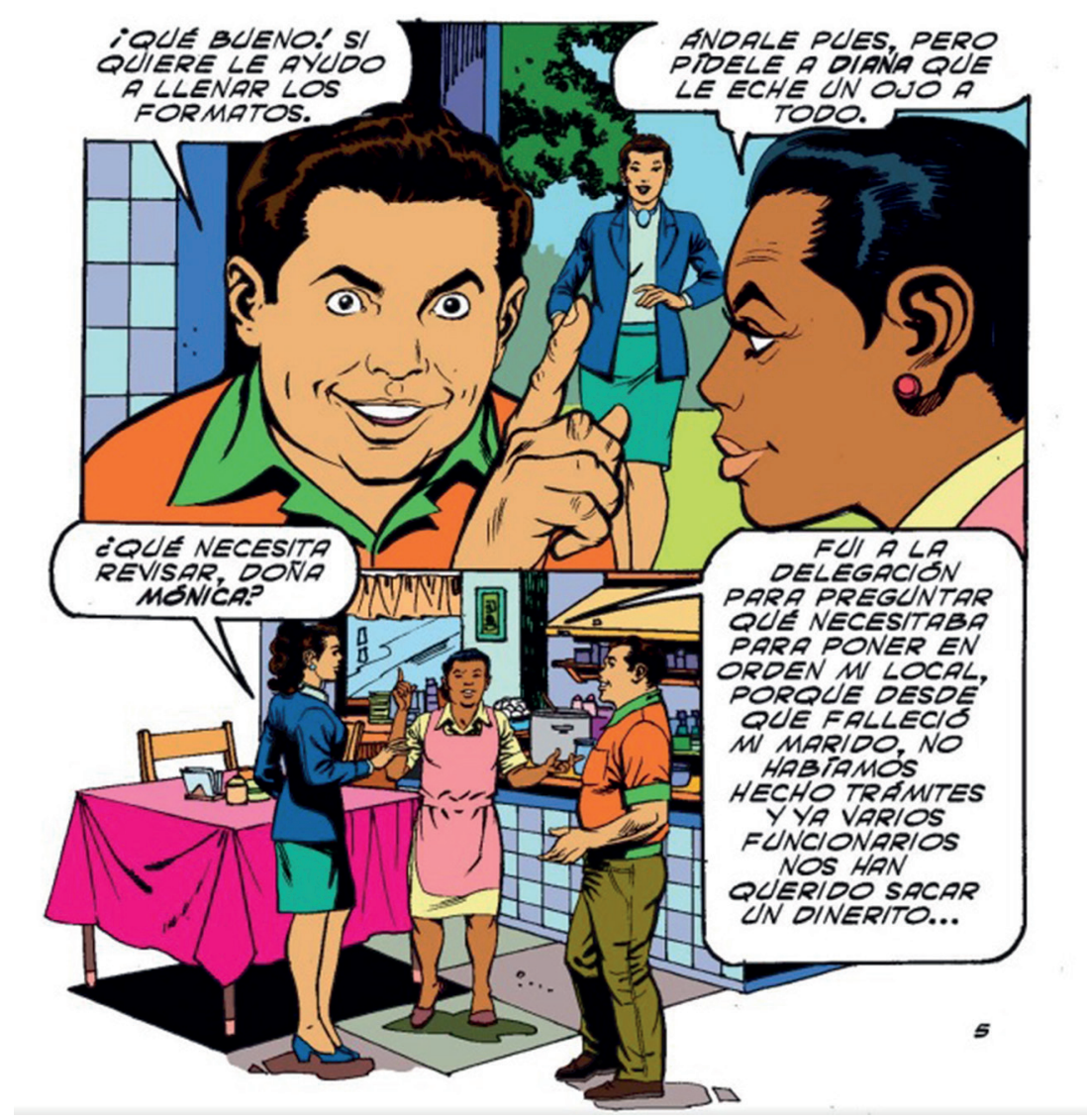

FIG. 6. Personajes de Doña Mónica y de Diana. Suplemento especial Libro Anticorrupción. $\mathrm{HeVi}$, 15 de febrero de 2017 , p. 5.

La segunda mujer en aparecer es Diana, personaje que funge como voz institucional, y del cual poco se sabe. Mientras que de los demás personajes se conoce su profesión, su idiosincrasia y la relación que tienen entre ellos (Gabriel y Omar son compañeros de trabajo; transportan la mercancía que compra Doña Mónica ${ }^{31}$ de Diana se sabe poco. Aparece en forma imprevista en la página 5 al ser nombrada; se desconoce su profesión, aunque por la forma en que habla e interpela a los otros personajes es posible intuir que se trata de una abogada o una funcionaria que trabaja en temas de transparencia y corrupción; su vestimenta es eminentemente formal y remite a las oficinas del ámbito público y legal (lo que reafirma la suposición anterior). Las tonalidades de su vestimenta son frías, con predominancia del azul, y toda su figura contrasta con el estereotipo de mujer característica de $E l$ Libro Vaquero. ${ }^{32}$

${ }^{31}$ Existe otro personaje más, del cual incluso se desconoce el nombre. Se lo presenta en plena conversación con Doña Mónica, por lo que es lógico intuir que son amigos o vecinos.

32 Por razones de espacio no profundizaremos en este punto, ya que no nos interesa El Libro Vaquero «en general», sino El Libro Anticorrupción, tal y como se lo dio a conocer. 
Retomando la distinción entre «punto de vista» y «voz narrativa» (o entre enunciado y enunciación) ${ }^{33}$ podemos ver que en el caso de Diana confluyen el tiempo de ficción (el de los personajes) y el narrativo (el de enunciación). Como se verá seguidamente, ella funge como una segunda voz institucional, reafirmando el discurso de El Libro Anticorrupción, por lo que es factible suponer la necesidad de cuidarla, separándola ligeramente del resto de los personajes. Ella está en su mundo de vida, participa de la experiencia de ficción del tiempo, pero lo hace desde los márgenes. Esto se vuelve especialmente evidente cuando rompe la diégesis narrativa (volveremos sobre esto).

\section{Individualización de responsabilidades}

Es importante resaltar el hecho de que en la historieta analizada se excluyen las cuestiones estructurales en torno a los actos de corrupción. El foco está puesto únicamente en las acciones individuales de los «ciudadanos» y su capacidad de agencia, poniéndolos en un plano que, al tiempo que iguala las responsabilidades, invisibiliza las desigualdades. A su vez, por momentos la retórica de Diana, en su dimensión prosódica, adquiere rasgos cuasi-admonitorios, convirtiéndola en un personaje moralizante. ${ }^{34}$

Podemos mencionar un caso en donde se aprecia este hecho en toda su magnitud. En la página 10, Diana explicita la postura que aquí llamamos de individualización de responsabilidades: «Todos podemos ser parte de un acto de corrupción. Ya sea participando activamente al ofrecer "mordidas" [soborno] a funcionarios, o queriendo saltarnos trámites». Vemos, así, que se hace recaer la responsabilidad en los propios individuos, desconociendo los condicionamientos estructurales que operan (de modo informal, tácito, implícito) en las prácticas cotidianas de todos los días- y que consisten, muchas veces, en tácticas ${ }^{35}$ de supervivencia desplegadas en contextos de pobreza, deterioro de la calidad de vida e inseguridad económica y social. Este solapamiento de las inequidades entre las clases dirigentes y las clases populares queda plasmado en la primera frase de Diana: «No porque ellos sean corruptos también tenemos que serlo». Esta frase encuentra una homología perfecta con lo dicho, en la presentación de la historieta, por la diputada Minerva Hernández: «Dicen que para bailar un tango se necesitan dos personas y para cometer un acto de corrupción también». ${ }^{36}$

Otro punto de suma importancia que se encuentra presente en esta página es la mímesis de mirada a cámara, la cual ha sido una de las mayores novedades discursivas que introdujeron los medios audiovisuales. El efecto de la mirada a cámara es la interpelación directa al espectador — en este caso, al lector-y su consecuente ruptura de la diégesis, o cuanto menos

33 Ricoeur, P. Tiempo y narración. Vol. 2. Estado de México, Siglo xxi Editores, 2008, p. 513.

34 Steimberg, O. (2013). Op. cit., p. 65.

35 Apelamos aquí a la clásica división entre tácticas y estrategias. De CerteAu, M. La invención de lo cotidiano. Artes de hacer. Vol. 1. Ciudad de México, Universidad Iberoamericana, 1996.

36 Animal Político. Op. cit. 
su suspensión ${ }^{37}$ La principal consecuencia de este acto es el reforzamiento del mensaje discursivo a través del contacto mediatizado. Y es la razón por la cual la mirada a cámara se ha convertido en uno de los principales recursos de los noticieros televisivos en su búsqueda por generar un efecto de verdad, anclado en la dimensión referencial. ${ }^{38}$

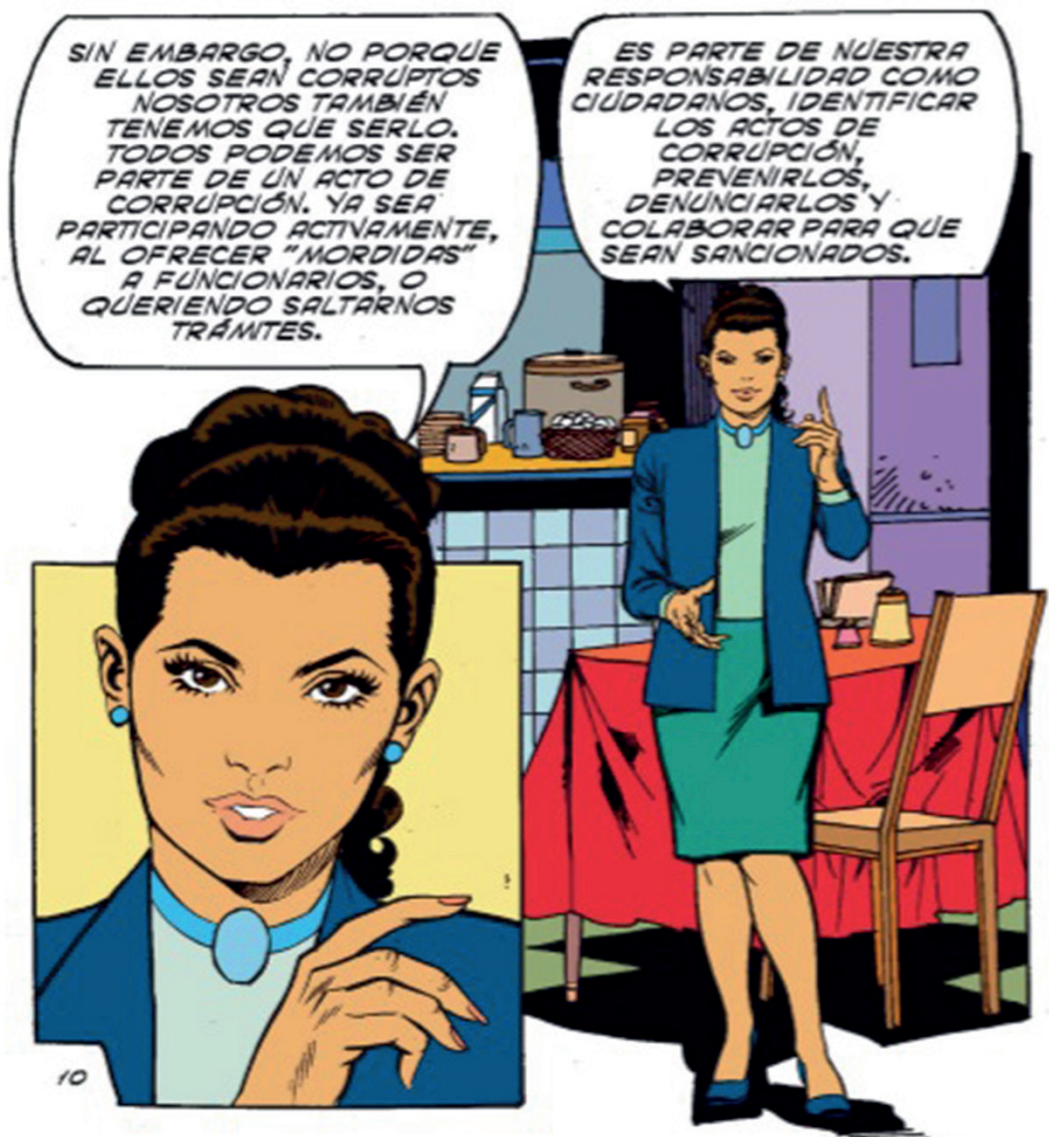

FIG. 7. Individualización de responsabilidades, Suplemento especial Libro Anticorrupción. $\mathrm{HeVi}$, 15 de febrero de 2017, p. 10.

En la página que estamos analizando, la representación gráfica de la mirada a cámara ${ }^{39}$ cumple la función de suspender la diégesis narrativa para interpelar directamente al lector: Diana ya no se dirige a Omar o a Gabriel (como sí lo hace en las páginas anteriores y posteriores), sino que apela al lector de la historieta. En la segunda viñeta, de plano general, reafirma su postura al señalar el deber ser del ciudadano: «Es parte de nuestra responsabilidad

37 Simon, J. Le filmique et le Comique. París, Albatros, 1979.

${ }^{38}$ Verón, E. Semiosis de lo ideológico y del poder/La mediatización. Buenos Aires, Facultad de Filosofía y Letras, Universidad de Buenos Aires, 1995.

39 Decimos que es representación porque está ausente la dimensión indicial de la mirada a cámara televisiva: aquí no hay mirada a cámara porque no hay cámara, no hay sujetos empíricos. Solo hay sujetos discursivos anclados puramente en la dimensión icónica. 
como ciudadanos, identificar los actos de corrupción, prevenirlos y colaborar para que sean sancionados». En esta frase se combinan las dos dimensiones que señalamos: la individualización de responsabilidades (nosotros, los ciudadanos en tanto suma de individualidades) y el deber de denunciar - sin indagar en las causas que los hacen posibles y que, incluso, en muchos casos los promueven, como el financiamiento de la política.

\section{Sujetos del discurso}

No se hace referencia aquí a los enunciatarios, sino a aquellos sujetos que son nombrados como responsables directos - lo que los acercaría más a ser objetos del discurso ${ }^{40}$ que sujetos propiamente dichos-. En el caso de El Libro Anticorrupción, entran en esta categoría los empresarios, los ciudadanos y los funcionarios públicos. Todos ellos aparecen en forma preponderante en la última ilustración. Es importante señalar que, si bien en dicha viñeta se hace referencia al político, la misma no puede ser considerada como condición suficiente para la construcción del político como un sujeto del discurso. Esto, ya que el político no es mencionado en ningún otro pasaje de la historia: siempre se hace referencia al funcionario público, ejemplificado a través de la figura del policía de tránsito y el inspector. Esta diferenciación, es importante notar, remite en forma directa a la distinción clásica entre el — «profesional» y el "político», ${ }^{41}$ por lo que quedan excluidos los agentes políticos pertenecientes al campo del poder. ${ }^{42}$

En la historieta, solo el funcionario público es acusado directamente de cometer actos corruptos; el «político» aparece nombrado al final, sin ninguna otra consideración. Por tanto, queda invisibilizado - y consecuentemente, excluido de responsabilidad.

Algo similar puede decirse de los empresarios, en cuanto que su mención es efímera y aparecen bajo la figura de un micro emprendedor, o comerciante. En efecto, el único personaje que remite al sector empresarial es Doña Mónica; pero como vimos, dadas sus características, este personaje está más cerca del comerciante, de aquellos trabajadores que viven en condición precaria, que de los grandes grupos empresariales. Nuevamente, se excluye a los agentes que conforman el campo del poder, haciendo recaer la responsabilidad de los actos de soborno sobre las clases populares.

Es imperioso señalar que la exclusión de los políticos y los grandes empresarios cobra mayor relevancia en el contexto actual. Ya se ha hecho mención a la crisis que afecta a los partidos políticos y a la clase dirigente. Sin embargo es posible ilustrar este momento con un ejemplo concreto que representa la relación entre los políticos y los grandes empresarios. Al momento en que se terminó de redactar este artículo, se debatía en la Cámara de Diputados (la

40 Foucault, M. El orden del discurso. Buenos Aires, Tusquets, 1999.

${ }^{41}$ Weber, M. «La política como vocación», en El Político y el Cientifico. Madrid, Alianza Editorial, 2005.

${ }^{42}$ Bourdieu, P. Campo de poder, campo intelectual. Itinerario de un concepto. Buenos Aires, Folios Ediciones, 1983. 
misma en donde se presentó la historieta) una «contrarreforma» para dejar sin efecto varios artículos de la Ley Federal de Telecomunicaciones y Radiodifusión (LFTR), ${ }^{43}$ aprobada por la misma cámara. Esto, en virtud de las presiones y campañas emprendidas por los principales grupos televisivos del país (Televisa y Tv Azteca), en un año pre-electoral.

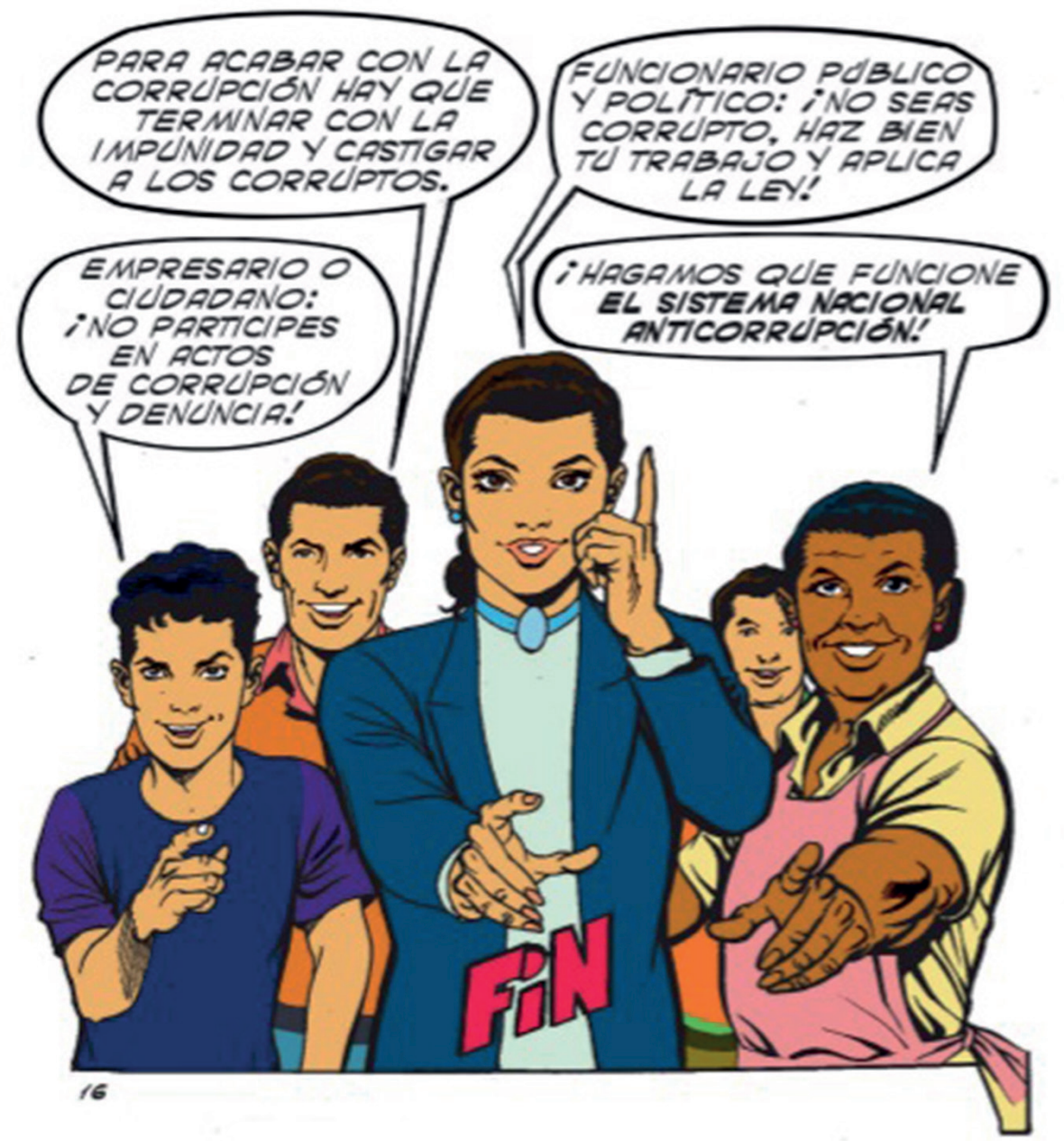

FIG. 8. Sujetos del discurso. Suplemento especial Libro Anticorrupción. HeVi, 15 de febrero de 2017, p. 16.

En la Figura 8 podemos ver cómo se expresa la individualización de las responsabilidades. Parece que la corrupción deriva solamente de las acciones individuales de sujetos (por ejemplo, empresarios, ciudadanos y funcionarios públicos) que actúan contra la ley sin otra razón que la del lucro personal y el desinterés por la vida democrática. Las causas estructurales - y, podemos agregar ahora, el político y el gran empresario- permanecen invisibilizadas, con la consecuente permanencia del statu quo.

43 Lo cual afectará principalmente a los derechos de las audiencias y a las radios comunitarias. 


\section{¿Qué nos deja esta historieta?}

Al regresar la mirada hacia la primera parte del artículo, es posible apreciar una situación cuanto menos paradójica. El lanzamiento de El Libro Anticorrupción se produjo en uno de los recintos emblemáticos del campo político (la Cámara de Diputados), el cual se ha visto cuestionado por múltiples escándalos, al punto de que sea un lugar común hablar, en diversos foros, de la «crisis de los partidos políticos» —-fenómeno que puede explicar, en parte, el crecimiento en intención de voto que en los últimos tiempos mantienen los candidatos independientes.

En una primera impresión podría significar que el evento en sí constituye un paso positivo en el combate contra estos delitos, en la medida en que se lleva a cabo en uno de los espacios más cuestionados. Sin embargo, esta apreciación pecaría de imprudente. Al examinar atentamente el discurso de la historieta vemos que son justamente los sujetos de este ámbito, es decir, los propios políticos - aquellos sujetos que ofician de público en el momento mismo del lanzamiento- quienes se encuentran ausentes de él. La individualización de las responsabilidades trae aparejada la invisibilización de la responsabilidad política, ya sea esta de tipo estructural o individual. Tampoco se muestran las consecuencias de la corrupción, la cual parecería seguir aislada del mundo de vida de los ciudadanos: el discurso apelativo de la historieta redunda en la obligación de no ser cómplice de un acto ilícito y denunciarlo (no se ofrece ninguna otra justificación aparte del «deber» de los ciudadanos). Y lo que quizás resulta aún más grave: queda invisibilizado el propio SNA, ya que no se proporciona ninguna información acerca de su funcionamiento, sus características, su emplazamiento físico, sus teléfonos de contacto o su página web. Solo se afirma que existe y que se debe denunciar la corrupción y cooperar cuando se requiera.

Hasta qué punto estas deficiencias son meros accidentes de políticas públicas, provocados por la ineficiencia o el desinterés de los responsables, o por el contrario cumplen la función de poner a salvaguarda al sector más imbricado en este tipo de delitos (las estructuras políticas y económicas que conforman el campo del poder), son preguntas que aquí no es posible responder en forma satisfactoria. Pero que indudablemente requieren una especial atención, en la medida en que afectan a la calidad democrática del México contemporáneo. 


\section{Hemerografía}

Animal Político. «¿Un Libro Vaquero para entender (y combatir) la corrupción?», en Animal Politico, 1 de marzo de 2017. Disponible en http://www.animalpolitico.com/2017/03/ libro-vaquero-corrupcion/

Associated Press. «La Biblioteca Pública de Denver veta las historietas E1 Libro Vaquero, El Libro Policiaco y otras dos», en La Crónica, 26 de agosto de 2005. Disponible en: http://www.cronica.com.mx/notas/2005/198922.html

ETHOS «Suplemento especial Libro Anticorrupción. ¿Qué hacer para combatir la corrupción?", en El Libro Vaquero, 15 de febrero de 2017.

INEGI. «Módulo sobre lectura (Molec). Principales resultados febrero 2017», en Instituto Nacional de Estadística y Geografía. Disponible en http://internet.contenidos.inegi.org. $\mathrm{mx} /$ contenidos/productos/prod serv/contenidos/espanol/bvinegi/productos/nueva estruc/promo/resultados molec feb17.pdf

Liceaga, E. «Libros Vaqueros», en Letras Libres, 13 de noviembre de 2015. Disponible en http://www.letraslibres.com/mexico-espana/libros-vaqueros

López Parra, R. «El Libro Vaquero, un clásico de la cultura popular», en Revista Mexicana de Comunicación, Núm. 99, junio - julio, 2005. Disponible en http://mexicanadecomunicacion.com.mx/rmc/2012/06/25/el-libro-vaquero-un-clasico-de-la-cultura-popu$\underline{\text { larl }}$

Murillo, C. «E1 Makeover del Vaquero», en Revista Expansión, 9-22 de octubre de 2015. Disponible en https://issuu.com/ellibrovaquero/docs/exp-1176-libro vaquero

Ocampo, M. «Libro Vaquero: odiado y amado, sigue galopando», en Sin Embargo, 12 de abril de 2013. Disponible en: http://www.sinembargo.mx/12-04-2013/583742

Rodríguez Beltrán, J. L. «Análisis de los problemas expresivos del cómic», en Revista Interuniversitaria de didáctica. 2009. Disponible en: http://revistas.usal.es/index. $\mathrm{php} / 0212-5374 /$ article/view/4174

SDPnoticias. «E1 Bronco deja claro que el Libro Vaquero es su favorito» en SDPnoticias.com, 24 de octubre de 2016. Disponible en https://www.sdpnoticias.com/local/nuevo-leon/2016/10/24/el-bronco-deja-claro-que-el-libro-vaquero-es-su-favorito

Toca G., V. «El libro Vaquero, el western mexicano más leído», en Revista Expansión, 22 de abril de 2012. Disponible en https://expansion.mx/entretenimiento/2012/04/22/ el-libro-vaquero-el-western-mexicano-mas-leido 


\section{Bibliografía}

Aurrecoechea, J. M. y Bartra, A. Puros cuentos. La historia de la historieta en México 1934 - 1950. México, Conaculta - Grijalbo, 1993.

Bajtín, M. «El problema de los géneros discursivos», en Estética de la creación verbal. Ciudad de México, Siglo xxı, 1982.

Bourdieu, P. Campo de poder, campo intelectual. Itinerario de un concepto. Buenos Aires, Folios Ediciones, 1983.

Camacho Morfín, T. «Dibujar historietas. Una enseñanza fuera de la Academia», en Reyes, A. (coord.). La enseñanza del dibujo en México. Aguascalientes, Universidad Autónoma de Aguascalientes, 2014, pp. 335-358.

De Certeau, M. La invención de lo cotidiano. Artes de hacer. Vol. 1. Ciudad de México, Universidad Iberoamericana, 1996.

Foucault, M. El orden del discurso. Buenos Aires, Tusquets, 1999.

Ricoeur, P. Tiempo y narración. Vol. 2. Estado de México, Siglo xxi Editores, 2008.

Simon, J. Le filmique et le Comique. París, Albatros, 1979.

Steimberg, O. Semiótica de los medios masivos. El pasaje de los medios a los géneros populares. Buenos Aires, Atuel. Buenos Aires, 1998.

-Leyendo historietas: textos sobre relatos visuales y humor gráfico. Buenos Aires, Eterna Cadencia Editora, 2013.

Verón, E. Semiosis de lo ideológico y del poder / La mediatización. Buenos Aires, Facultad de Filosofía y Letras, Universidad de Buenos Aires, 1995.

Weber, M. «La política como vocación», en El Político y el Científico. Madrid, Alianza Editorial, 2005.

Zavala, L. «Los componentes formales, estructurales e ideológicos de la historieta», en DeSignis. Semióticas gráficas, n. ${ }^{\circ}$ 21, (2013), pp. 72-81.

\section{RECURSOS AUDiovisUALES}

Núñez, G. El Libro Vaquero mexicano seduce en Praga. [Podcast]. Radio Praha en español, 27 junio de 2012. Disponible en: http://www.radio.cz/es/rubrica/panorama/el-libro-vaquero-mexicano-seduce-en-praga

Warketin, G. y Risco A. El Libro Vaquero está de regreso [Podcast]. Programa Así las cosas, $\mathrm{W}$ radio, 2 de marzo de 2017. Disponible en http://ethos.org.mx/es/el-libro-vaquero-esta-de-regreso/ 